\title{
Altyapı Sorunlarına Yenilikçi Çözüm Önerilerinin Getirilmesi
}

\author{
Muhammed Ernur Akıner ${ }^{1 *}$, İlknur Akıner ${ }^{2}$ \\ 1*Akdeniz Üniversitesi, Teknik Bilimler Meslek Yüksekokulu, Çevre Koruma Teknolojileri Bölümü, Antalya, Turkey, (ORCID: 0000-0002-5192-2473), \\ ernurakiner@akdeniz.edu.tr \\ ${ }^{2}$ Akdeniz Üniversitesi, Mimarlık Fakültesi, Mimarlık Bölümü, Antalya, Turkey, (ORCID: 0000-0002-9550-146X), ilknurakiner@akdeniz.edu.tr
}

(İlk Geliş Tarihi 7 Ekim 2021 ve Kabul Tarihi 25 Aralık 2021)

(DOI: 10.31590/ejosat.1006062)

ATIF/REFERENCE: Akıner, M. \& Akıner, İ. (2021). Altyapı Sorunlarına Yenilikçi Çözüm Önerilerinin Getirilmesi. Avrupa Bilim ve Teknoloji Dergisi, (31), 755-763.

\begin{abstract}
$\ddot{\mathbf{O z}}$
İstanbul'da hızlı nüfus artışı ve yeterli denetimlerin olmaması nedeniyle 90'lı yıllara kadar çarpık yapılaşmanın hızla arttı̆̆ görülmüştür. 1995'den günümüze kadar çarpık yapılaşmanın önlenmesi amacıyla teknolojiden yararlanılarak denetimler artırılmış ve toplu konut yapımlarına hız verilmiştir. Şehrin imara açık bölgelerinde her tür altyapısı planlı olan uydu kentler oluşturulmaktadır. Son yıllarda uydu kentlerin kurulmasına hız verilmesine rağmen, ilin büyük bir bölümünde geçmişten kalan çarpık yapılaşma mevcuttur. Sürdürülebilir kalkınma; yüksek altyapı maliyetlerinin minimuma indirilmesi, kentsel planlama ve altyapı hizmeti veren kurumların birlikte planlarını oluşturması ile mümkündür. Ancak İstanbul'un büyük bir bölümünde şehirleşme süreci tamamlandığından bunun için geç kalındığı da anlaşılmaktadır. Bu noktada öncelikle yapılması gereken mevcut altyapı sorunlarının çözümünün bir merkezden gerçekleştirilmesidir. Yani su ve kanalizasyon, elektrik, telefon ve doğalgaz altyapı hizmetlerini sunan kurumlar ile belediyelerin ulaşım hizmetleri arasında koordinasyonun bir merkezden sağlanmasıdır. Altyapılar genellikle yollar ve kaldırım altlarına inşa edildiğinden ilgili belediyelerin ulaşım altyapısı da dikkate alınmalıdır. Yeraltı altyapı sistemlerinin sıklıkla hasar görmesi ve kamu hizmetlerine yönelik artan talep nedeniyle sürekli olarak yenileme gerektirmesi, daha verimli kurulum, denetim, onarım, rehabilitasyon ve sonuç olarak geleneksel altyapı hizmetlerinin değiştirilmesi gerekliliğini artırmıştır. Geleneksel açık inşaat yöntemleriyle, asfalt yenileme, kaldırımlar, çevre düzenlemesi ve tuğla döşeme gibi zemin yüzeylerini restore etme ihtiyacı nedeniyle doğrudan maliyetler büyük ölçüde artmaktadır. İstanbul ilinde su, elektrik, doğalgaz ve telefon gibi altyapı sistemlerinin bir arada döşenebilmesini sağlayan "Utility Tunnel" olarak bilinen "kapaklı betonarme altyapı tünellerinin" tesis edilmesi durumunda tamir ve yenilemenin çok daha kolay yapılabileceği düşünülmektedir. Yapılması öngörülen çalışmada nihai hedef birçok altyapı sorunu senaryosunun oluşturulabileceği, problemler ortaya çıkmadan gerekli çözümlerin bulunabileceği ve koordinasyonu sağlayan bir merkezin oluşturulması ile İstanbul'un altyapı sistemlerine özgü kısa ve uzun vadeli yenilikçi ve ekonomik çözümlerin bulunmasidir.
\end{abstract}

Anahtar Kelimeler: Sürdürülebilirlik, Altyapı Tüneli, Yenilikçi Altyapı, Tünel Sistemler.

\section{Innovative Solution Suggestions to Infrastructure Problems}

\begin{abstract}
Istanbul's unplanned buildings expanded significantly until the 1990s due to high population expansion and insufficient inspections. Inspections have been enhanced, and mass home development has been expedited from 1995 to the present by utilizing technology to avoid uncontrolled construction. Satellite cities with various types of infrastructure are being developed for sections of the city that are available for development. Although the development of satellite cities has been expedited in recent years, a significant portion of the province still has a skewed settlement from the past. Sustainable development is only feasible if entities that provide urban planning and infrastructure services collaborate to design their plans. However, because the urbanization process has been finished in a significant portion of Istanbul, it is recognized that this is too late. The initial step at this stage is to address current infrastructure
\end{abstract}

*Sorumlu Yazar: ernurakiner@akdeniz.edu.tr 
issues from a central location. In other words, it is the coordination from the central area of the institutions supplying water and sewage infrastructure, power, telephone, and natural gas infrastructure, and municipal transportation services. Because infrastructures are typically developed beneath roads and pavements, the appropriate towns' transportation infrastructure should also be considered. The need for more effective installation, inspection, repair, rehabilitation, and ultimately replacement of traditional infrastructure services has grown as a result of the frequent destruction of subsurface infrastructure systems and the necessity for constant renewal owing to rising utility demand. Due to the necessity of replacing ground surfaces such as asphalt regeneration, sidewalks, landscaping, and bricklaying, direct costs of traditional open-cut construction methods rise dramatically. It is believed that installing "reinforced concrete infrastructure tunnels" known as "Utility Tunnels," which allow electricity, telephone, natural gas, and water infrastructure systems to be linked together, will make maintenance and renewal considerably easier. The project's ultimate goal is to establish a center where many infrastructure problem scenarios can be created and necessary solutions can be found before problems arise, as well as to establish a center that provides coordination and finds short and long-term innovative and economical solutions specific to Istanbul's infrastructure systems.

Keywords: Sustainability, Infrastructure Tunnel, Innovative Infrastructure, Tunnel Systems.

\section{Giriş}

Kırsal tarım topluluklarıyla taban tabana zitlık içinde olan kentleşme eğiliminin 2050 yılına dek \%70'lik bir oranda artacağ öngörülmektedir (Hall \& Pfeiffer, 2013). Dünya çapında kentsel arazi kullanımındaki bu mevcut eğilimler, büyük ölçüde yer üstü genişlemeye odaklanmaktadır ve birçok kentsel merkezde, yeraltı alanı şu anda yeterince kullanılmamaktadır (Sterling vd., 2012). Sürdürülebilir kalkınmayı sağlamanın bir yolu olarak yüzeydeki artan arazi baskılarının neden olduğu kentsel ortamlarda yeraltı alanını kullanma ihtiyacının karşılanması Brundtland (1987) raporunda dile getirildikten sonra daha da yaygın bir şekilde kabul görmektedir (Parriaux vd., 2007). Gaz, su, kanalizasyon boruları, elektrik ve telekomünikasyon kabloları gibi kamu hizmetleri ağları yerin üstünde ve altında geliştirilmektedir. Kentsel alanlardaki yer üstü hizmetleri, estetik sorunlar, sınırlı kentsel alanın işgali, sınırlı erişilebilirlik alanı ve kasırga, aşırı yüksek veya düşük sıcaklık gibi hava değişikliklerine maruz kalan kamu hizmetleriyle ilgili güvenlik sorunlarına neden olmaktadır. $\mathrm{Bu}$ nedenle, altyapı tünelleri özellikle kentsel alanlarda, hizmet ağlarının geliştirilmesi açısından oldukça fayda sağlamaktadır (Gagnon vd., 2008).

Sosyal ve çevresel faktörler dikkate alındığında, açık kesim altyapı yenileme teknikleri, istenmeyen kirlilik ve trafik kesintileri nedeniyle toplum, iş dünyası ve taşıtlar üzerinde olumsuz etkilere sahiptir (Shahrour vd., 2020). Yeralt1 altyap1 sistemlerini minimum yüzey bozulmasıyla onarmak, yenilemek veya eklemeler yapmak için kullanılan kazısız teknolojiler, mevcut açık kesme yöntemlerine uygun bir alternatif sunar. $\mathrm{Bu}$ çalışmada karar vericilere bazı durumlarda kazısız teknolojiyi en ekonomik alternatif haline getirebilmek çin bu maliyetleri doğrudan sermaye maliyetleriyle birleştirmeyi düşünmeleri önerilir. Ayrıca verimlilik, işçi güvenliği ve yapısal sorunlar, kazısız teknolojinin yeraltı altyapı sistemleri için daha verimli bir yöntem olduğunu göstermiştir. Sonuç olarak, Kazısız Alt Yapı Sistemi, şehirlerin altyapılarını kurmaları için geleneksel açık-kesim kamu hizmetleri kurulumuna kıyasla daha sürdürülebilir bir yöntemdir (Yin vd., 2020). Bu makalede ayrıca Yatay Yönlü Sondaj (HDD) kullanılarak nehir gibi engellerin altından ara bağlantıların inşasının da mümkün olabileceği belirtilmiştir.

$\mathrm{Su}$, elektrik, doğalgaz ve telefon gibi altyapı sistemlerinin bir arada döşenebilmesini sağlayan kapaklı betonarme altyap1 tünellerinin tesis edilmesi durumunda tamir ve yenileme çok daha kolay yapılabilmektedir. Bu tip sistemler esasen yurtdışında gelişmiş ülkelerce kullanılmaya başlanmıştır (Riera \& Pasqual, 1992). 1800'lü yılların başında kömürden üretilen şehir gazını binalara iletmek amaciyla kurulan yer altı gaz şebekesi sı ̆ derinlikte yaya yolunun altına gömülmüştür ve 19. yüzyıldan itibaren yaygın olarak kabul edilen bir çözüm olmuştur (Rogers \& Hunt, 2006). Altyapı tünelleri, su iletimi, telekomünikasyon, gaz tedarik sistemi vb. gibi birçok altyapı hattını içeren bir entegrasyon sistemidir, bu nedenle toplumun ve ekonominin sağlıklı gelişimini sürdürmek için kilit bir faktör olarak görülmektedir (Yang \& Wang, 2013). Günümüz iletişim teknolojileri kapsamında akıllı altyap1 sistemleri de oluşturulabilmektedir. Bu sayede akıllı altyapı sistemlerinde kullanılan sensörlerle toplanan veriyi ileten, analiz eden, ölçen, izleyen ve daha gelişmiş performans ve kullanıcı deneyimi için kullanıcı talepleri ve çevredeki değişikliklere akıllı şekilde yanıt verebilen ve kamusal değer oluşturan bir yapı oluşturulmaktadır. Kullanım ömrü boyunca, doğru yerde kullanıldığı ve doğru sayıda kamu hizmetini barındırdığı sürece, altyapı tünellerinin ekonomik olarak daha sürdürülebilir bir kamu hizmeti sağlayabileceği anlaşılmaktadır (Hunt vd., 2014).

İstanbul için önerilen kapaklı betonarme altyapı tünellerinin kurulmasıyla su, elektrik, doğalgaz ve telefon altyapısının yenilenmesinin çok daha kolay olması beklenmektedir. $\mathrm{Bu}$ nedenle altyapı hizmetlerinin birleştirilmesi ve tek bir merkezden yönetilmesi için prefabrike altyapı tünelleri (Utility Tunnels) öncelikli olarak değerlendirilmektedir. Ancak İstanbul'un coğrafi ve arazi kullanım yapısı düşünüldüğünde hemen akla dar ve dik yokuşlu sokaklar gelmektedir. Önerilen altyap1 tünelleri, içeride bir veya birkaç kişinin rahatça çalışabileceği şekilde tasarlanmalıdır. Ayrıca bu ölçekteki betonarme tünelin dar ve dik bir cadde veya kaldırımın altına yerleştirilmesi mümkün değildir. Bunun yerine sokaklarda kazısız teknoloji gibi alternatif altyapı sistemleri, ana sisteme bağlantı amaçlı kullanılabilir. Özetle, altyapı tünellerinin alternatif altyap1 sistemleri ile desteklenmesi gerekmektedir. Bunu yaparken alternatif altyap1 sistemlerinin izlenmesi de dikkate alınmalıdır. Fiber optik sensörler, başta boru hatları olmak üzere altyapı sistemlerinin sağlığının izlenmesine yardımcı olur. Alternatif altyapı sistemlerinin neler olabileceğine karar vermeden önce İstanbul ile aynı özellikleri gösteren bazı şehirlerin incelenmesi gerekmektedir. Bu amaçla sokakları dar ve nüfusu yoğun dünya şehirlerinde kullanılan kazısız boru ve kablo döşeme teknolojileri araştırılmıştır.

İstanbul için bu tünellerin araç yükünün maksimum olduğu yolun ortasından değil, kaldırım ve yol kenarları hizasında simetrik olarak tesis edilmesi düşünülmektedir (Bkz. Şekil 1). 
University of Washington - Engineering Services (2017) tarafından uygulanan örnek en kesitte boyutlandırılmış tip kanal sistemi Şekil 2'de görülmektedir. Altyapı sorunlarına yenilikçi bir çözüm oluşturan bu sistemin, kent açısından önemli faydalar sağladığı anlaşılmaktadır (Yang \& Wang, 2013; Gagnon vd., 2008; Rogers \& Hunt, 2006). Bu sistemin faydalar1:

* Düşük kurulum maliyeti. yapılmasi.

* Altyapı iletişiminin tüm hizmetler için tek noktadan

* Farklı zamanlarda çok sayıda bağlantı gerektiren teçhizatlarda daha fazla esneklik.

* Daha verimli, zaman tasarruflu uygulama.

* Daha az kazı.

* Sağlıklı, güvenlikli ve kaliteli sistem.

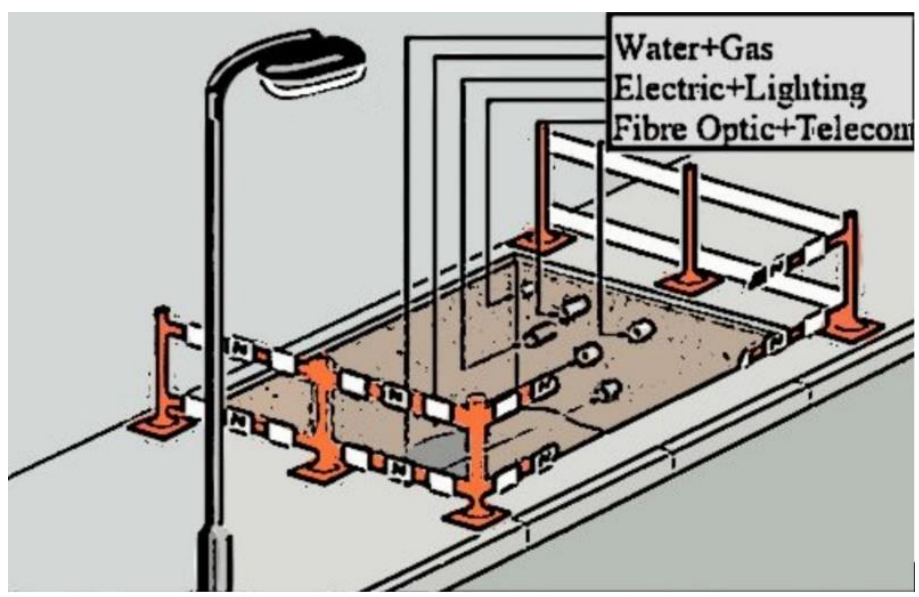

Şekil 1. Kaldırım ve yol kenarları hizasında döşenen altyapı için temsili resim, tüm altyapı sistemleri bir arada.

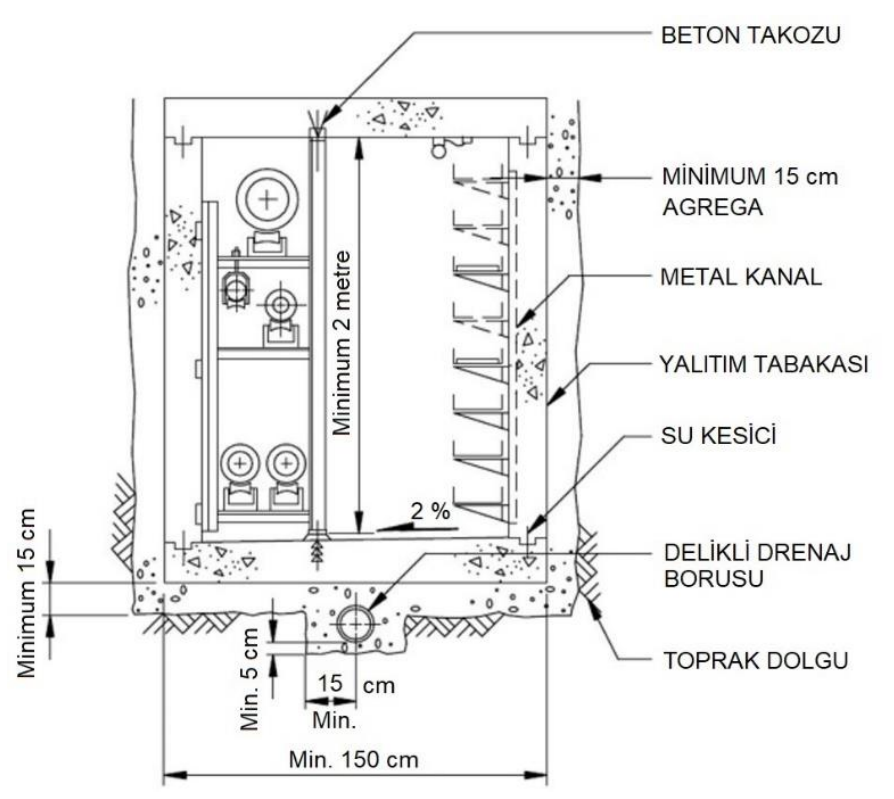

Şekil 2. Örnek betonarme kanal en kesiti.

Kazısız teknoloji, altyapı tünellerinin uygulama kolaylığ için yenilikçi bir yaklaşımdır. Zamandan ve işçilikten tasarruf gibi birçok avantaj sağlar. Ayrıca, geleneksel altyapı sistemlerinin uygulanamadığı bazı alanlarda kazısız teknoloji e-ISSN: 2148-2683 yardımcı olabilir. Altyapı sistemi yolun her iki tarafına yerleştirilmek isteniyorsa ve tek hat üzerinde devam etmesi için belirli noktalarda birleştirilmesi gerekiyorsa, yan bağlantı amaçlı fazladan kazılara ihtiyaç duyulmaktadır. Bu tür bir işlem çok pahalı olduğu için uygun değildir ve ayrıca bir hafriyat nedeniyle belirli bir süre nakliyeyi engeller.

Özellikle İstanbul'un dar ve dik yokuşlu sokakları için kapaklı betonarme altyapı tünellerinin kurulması pek mümkün olmayacaktır. $\mathrm{Bu}$ nedenle, en iyi yaklaşım, altyapının uygulanmasında optimum sonucu elde etmek için birden fazla yenilikçi teknolojinin kombinasyonu olabilir. $\mathrm{Bu}$ çalışmada kazısız boru ve kablo döşeme teknolojileri ele alınmaktadır. Ayrıca, güvenlik sorunları göz önünde bulundurularak, altyapı sistemlerinin sağlığının izlenmesine yardımcı olan fiber optik sensörlerin uygulanması araştırılmaktadır.

\section{Materyal ve Metot}

\subsection{Altyapı Tüneli (Utility Tunnel) Sistemi}

Utility Tunnel olarak da bilinen bu tüneller bir yada birkaç kişinin rahatlıkla çalışabileceği ölçülerde boyutlandırılmalıdır (AbouRizk vd., 1999; Canto-Perello \& Curiel-Esparza, 2001; Canto-Perello vd., 2009). Örneğin, Amerika Birleşik Devletleri Capitol Ziyaretçi Merkezi (United States Capitol Visitor Center) için inşa edilen Utility Tunnel Şekil 3'de görülmektedir. İstanbul için önerilen sistemde oluşturulacak betonarme trapez ya da dikdörtgen en kesitli tünel üzerinde bundan farklı olarak toprak bulunmayacaktır. Utility tunnel belli aralıklarla betonarme bir kapakla örtülür, bu aynı zamanda tünele giriș noktasıdır. Su, kanalizasyon, elektrik, gaz, telefon ve merkezi 1sitma içeren altyapı tüneli örneği ve örnek bir giriş ise Şekil 4 ve 5 'te gösterilmektedir.

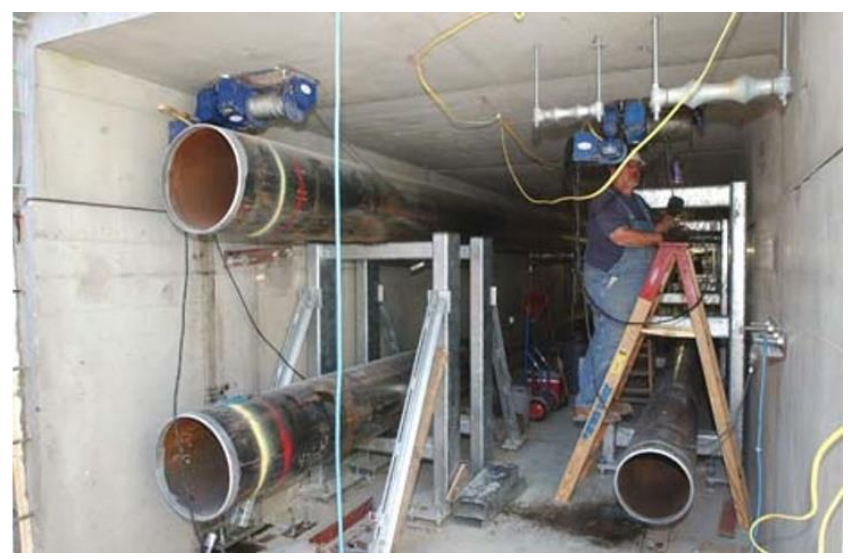

Şekil 3. United States Capitol Visitor Center Utility Tunnel iç görünüş (Capitol Visitor Center Project Office, 2005). 


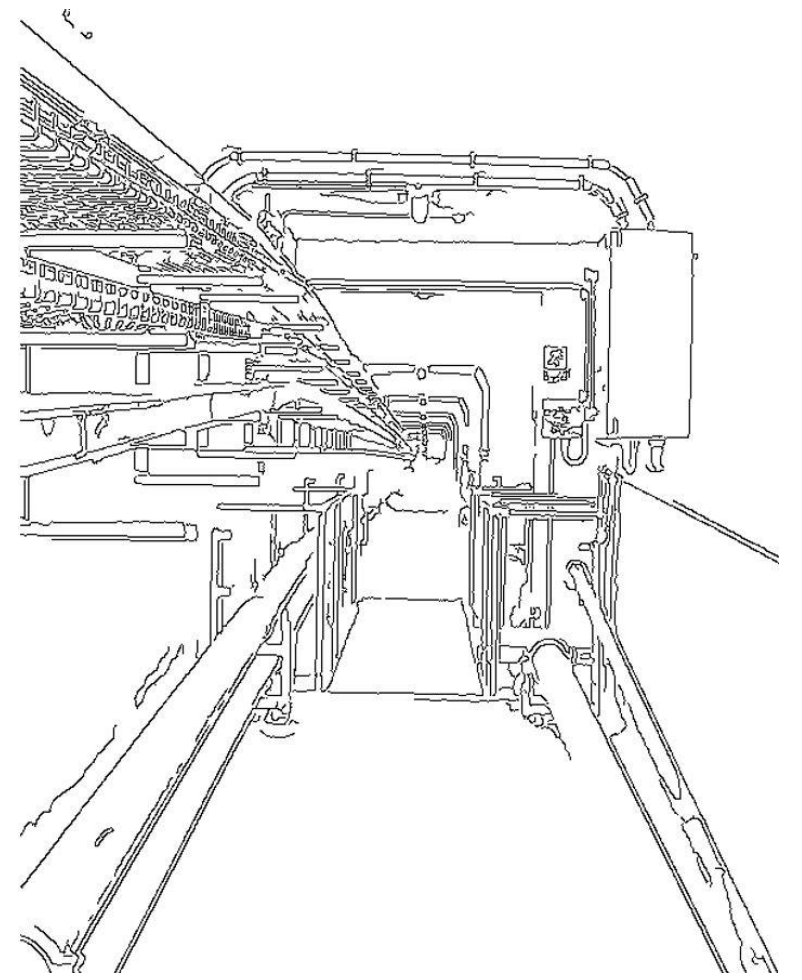

Şekil 4. Su, kanalizasyon, elektrik, gaz, telefon ve merkezi isıtma içeren temsili altyap tüneli örneği .

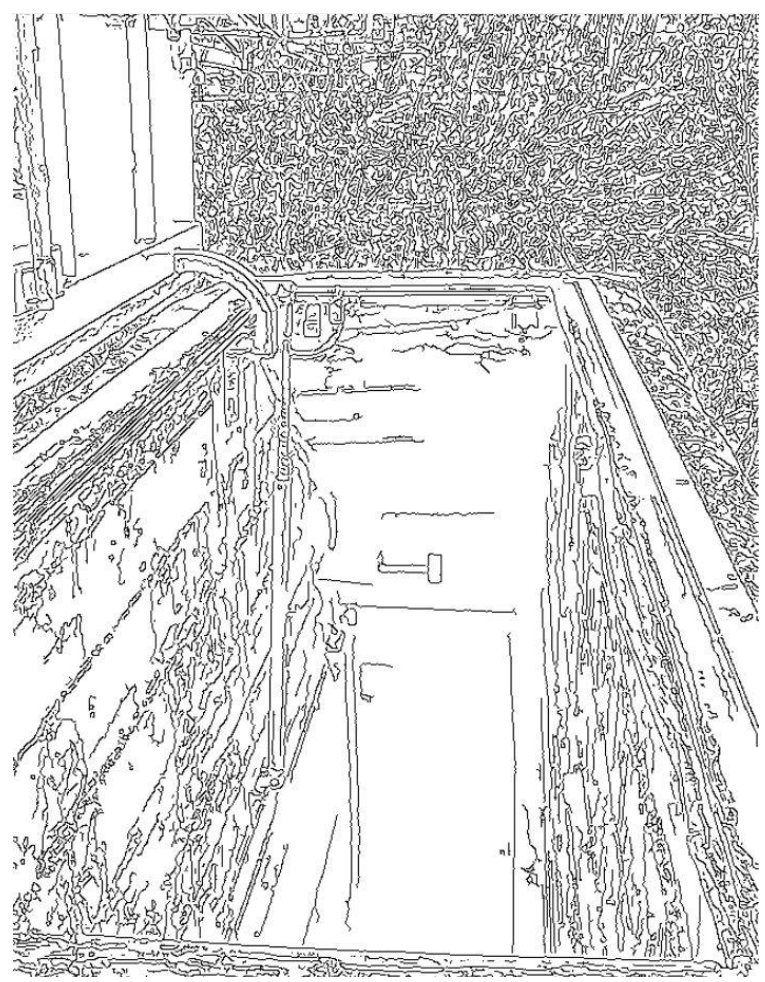

Şekil 5. Temsili altyapı tünel girişi örneği .

Prefabrike altyapı tünelleri fabrikada hazırlanıp sahaya taşınabilmekte ve kolaylikla monte edilebilmektedir (Ruiz, 2009). Sistemin pratikliğini de yansıtan temsili uygulama örneği Şekil 6'da görülmektedir.

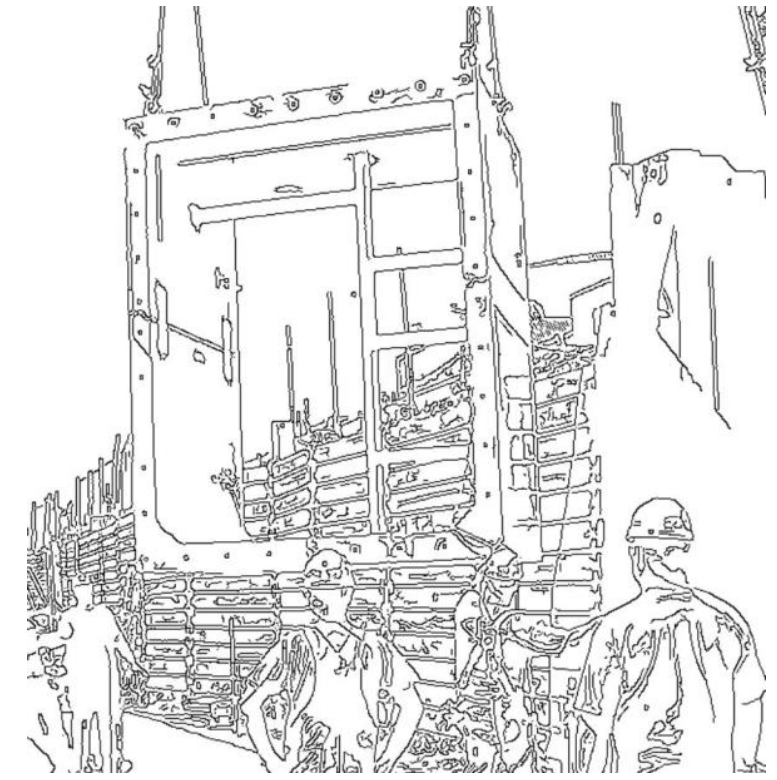

Şekil 6. Prefabrike altyapı tünelinin taşınması ve birleştirilmiş hali.

\subsection{Kazısız Alt Yapı Sistemi}

Özellikle iki lokasyonun konvansiyonel bir kazı ile yatay bağlanmasına engel olan yerlerde kazısız boru ve kablo döşeme teknolojileri kullanılmaktadır. Örneğin iki yer arasında nehir varsa bağlantı nehrin altından yapılmalıdır. Ancak bir tünelin kazılması uzun zaman alır ve toprağın su altındaki stabilitesi aşılması zor bir konu olduğundan kalifiye işçilik gerektirir. Bu çalışma, bu yenilikçi teknolojinin dar, dik sokaklarda ve yoğun nüfuslu alanlarda da başarıyla kullanılabileceğini ortaya koymaktadır. Bu amaçla Birleşik Arap Emirlikleri, Kanada ve ayrıca Çin'in dar sokakları ve yoğun nüfuslu Şanghay ve Chongqing şehirleri de dahil olmak üzere birçok örnek araştırılmıştır (Ariaratnam vd., 2006; Ariaratnam vd., 1999; Ma \& Najafi, 2008; Zaneldin, 2007). Araştırmalar, bu teknolojinin dar ve dik sokaklarda altyapının uygulanmasıyla ilgili birçok sorunu kazıya ihtiyaç duymadan aşmak için oldukça uygun olduğunu göstermektedir.

\section{Araştırma Sonuçları ve Tartışma}

Açıkçası, ilk yatırım maliyet geleneksel uygulamalar düşünüldüğünde daha büyük olacaktır. $\mathrm{Bu}$ noktada maliyeti düşürmek için ne yapabileceğimizi düşünmemiz gerekir. Örneğin makina kirası, işçi mesaisini düşürmek amacıyla hızlı kazı yapabilen özel makineler kullanılabilir, zaten kesit belli büyüklükte olacağından tip kazı yapılarak kazı maliyeti azaltılabilir. Nüfus yoğunluğunun fazla olduğu yerlerde altyapı sisteminin rehabilitesi ilk etapta mevcut sistemin yeni sisteme entegre edilmesi yoluyla sağlanabilir. Kalabalık yerlerde yeni sistem için yapılan kazılarda, eski sistemin hasar görmesi, halkın su, elektrik, gaz gibi ihtiyaçlarında aksamaya gidilmesine neden olacaktır. Hizmet sürekliliğini sağlamak ve kazı sırasında altyapının zarar görmesini önlemek amacı ile mevcut altyapı haritasının tamamının son derece detaylı şekilde bir araya toplanmas1 ve incelenmesi zorunludur.

Önerilen altyapı tünellerinin kaldırım hizasında olması düşünülmektedir. Maliyeti azaltıcı bir öneri de üst prefabrike betonarme kapağın desenli olarak dökülmesidir. Desenli betonarme kaldırım yolu uygulamalarının örneklerine dünyada sıkça rastlanmaktadır, kaldırım taşı görünümü verilmiş beton 
yüzey hem maliyeti azaltacaktır hem de estetik anlamda herhangi bir kayba uğranmasının da önüne geçilmiş olacaktır (Rivard Concrete, 2014; Bennett, 2005).

Geçmişte, doğal gaz boru hatları doğrudan yolların altına gömülürdü, toprağın havayı izole etmeye yardımcı olmasına rağmen, boru korozyonu riski önemli ölçüde artmaktaydı (Li vd., 2019). Kapaklı betonarme altyapı tünelinin koruyucu etkisi ile boru hatlarının toprak ve yeraltı suyu erozyonu ile korozyona uğraması veya firtına, tayfun, deprem gibi doğal afetlerden zarar görmesi engellenebilmektedir (Wang vd., 2020). Havalandırma sistemi ve gelişmiş sensörler ile donatılan altyapı tüneli izole yapısı ile borularda korozyon riskini azaltmaktadır (Zhou vd., 2021). Elektrik çarpması, geleneksel elektrik kabloları için yaygın bir kazadır, ancak altyapı tünellerindeki kablolar nispeten kontrollü bir alanda düzenlenmiştir ve bu riski azaltmaktadır (Wu vd., 2021).

Bazı borularda, boru içinden geçen malzemenin donması, muhtemel gaz sızıntısı, elektrik kablolarıyla etkileşim vb. nedenlerle yalıtım gerekebilir (Canto-Perello \& Curiel-Esparza, 2006). Deformasyon durumunda potansiyel tehlike oluşturabilecek yalıtım malzemelerinin bakım onarım çalışmaları da ihmal edilmemelidir.

Kablo rafları erişilebilirliği kolaylaştırmak amacı ile duvarlara monte edilmektedir (Bkz. Şekil 7). Kalabalık kablo yığınları hava almayan ortamlarda 1S1 dağılımı sağlanamadığından yangın üretebilmektedir (Curiel-Esparza \& Canto-Perello, 2005). Kablo raf sistemi ile bu tehlikenin önüne geçilmiş olunmaktadır.

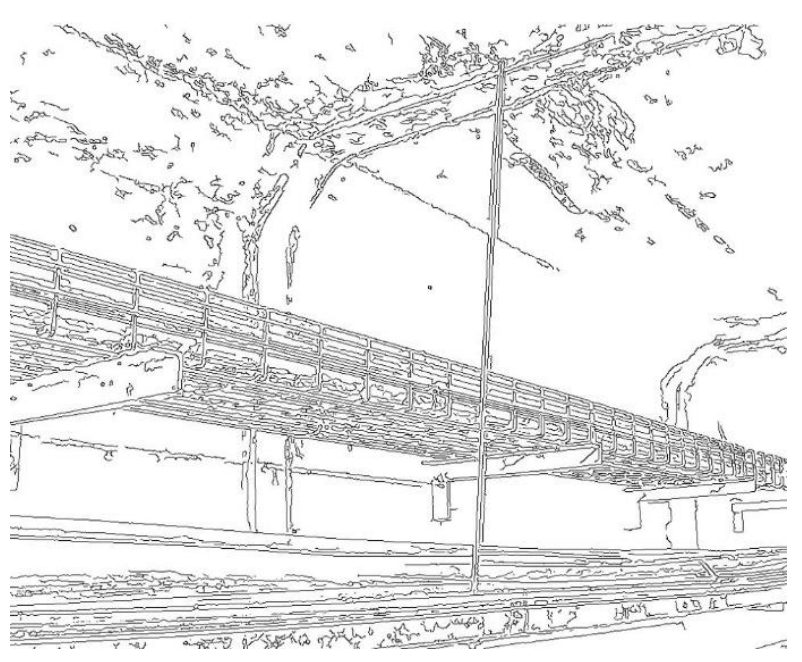

Şekil 7. Temsili kablo raflarl.

Altyapı tünelleri belli standartlara göre ve birçok etkene göre boyutlandırılmaktadır. İşçilerin rahat ve sağlıklı çalışmasını sağlayacak ortamın oluşturulması, kablo ve boruların etkileşimini engelleyecek şekilde sıralanması, montaj ve demonte işlerinin kolaylıkla yapılacağı geniş ortamın sağlanabilmesi gibi birçok faktör göz önüne alınarak örnek boyutlandırmalar yapılmış ve literatürde yer bulmuştur (CantoPerello \& Curiel-Esparza, 2001).

Bir işçinin rahatlıkla çalışabileceği ölçüde boyutlandırılan örnek altyapı tüneli ve boyutları Canto-Perello \& Curiel-Esparza (2001) tarafından belirlenmiştir. Raflar arasında bir işçinin çalışmasına engel olmayacak ölçüde yeterli genişliğin mutlaka sağlanması gerekmektedir.
Bir işçi kolaylıkla en üst rafa dahi ulaşabilmeli ve arızayı giderebilmelidir. Boyutlandırılma yapılırken buna dikkat edilmesi gerekmektedir.

Maksimum raf yüksekliği 190 cm'yi aşmamalıdır (CantoPerello \& Curiel-Esparza, 2001). Rafların derinliği fazla olamamalıdır, aksi halde kablolara ulaşım ve tamirat noktasında zorluklarla karşılaşılabilmektedir. Omuz hizası raf derinliğinin 30 cm'yi, omuz - göbek hizası arasındaki rafların derinliğinin 60 cm'yi, göbek hizası altındaki raflarda derinliğin 45 cm'yi geçmemesi önerilmektedir (Canto-Perello \& Curiel-Esparza, 2001).

Bir işçinin ergonomik olarak eğilmesini gerektirmeyecek şekilde onarım yapmasının sağlanması önemlidir. Raflar göbek hizasının altına düşürülmemelidir. Böylece işçinin yatay olarak kapladığı alan fazla olmayacak ve dar alanda rahatlıkla çalışabilecektir.

NIOSH (National Institute for Occupational Safety and Health) kaldırma denklemi (Bkz. Denklem 1) kullanarak rafların dikey konumuna göre farklı raf genişlikleri için önerilen ağırlık limitleri (Waters vd., 2007), Şekil 8'de görülmektedir.

$R W L=\frac{500}{20+S} \cdot\left(0.82+\frac{4.5}{V}\right)$

Denklem 1'de:

RWL; önerilen ağırlık limitleri (kp cinsinden $\left(\sim 100 \mathrm{~kg} / \mathrm{m}^{2}\right)$,

$\mathrm{S}$; rafların genişliğini,

$\mathrm{V}$; raf dikey konumunu belirtmektedir.

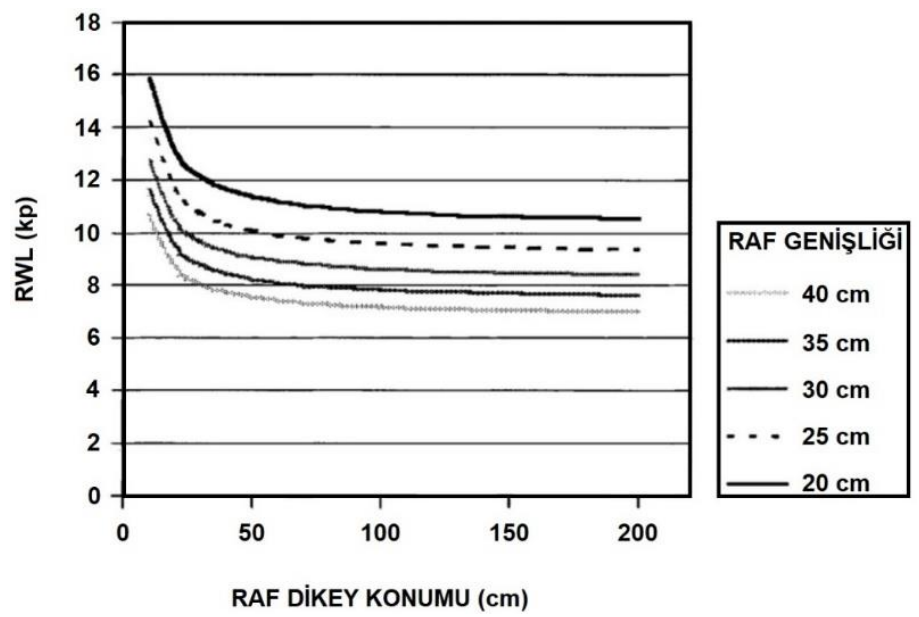

Şekil 8. Rafların dikey konumuna göre farklı raf genişlikleri için önerilen ă̆ırlık limitleri.

Her şeyden önce işçi ve teknik personelin sağlı̆̆ gelmektedir. $\mathrm{Bu}$ anlamda tünellerin içi aydınlatılmalı, havalandırılmalı ve tehlike anında kaçışı kolaylaştıracak, karanlıkta dahi görülebilen işaretlerin, telefon, yangın, acil müdahale ekipmanlarının standart olarak belli aralıklarla tünellere yerleştirilmesi gerekmektedir (Curiel-Esparza \& CantoPerello, 2005) (Bkz. Şekil 9 ve 10). 


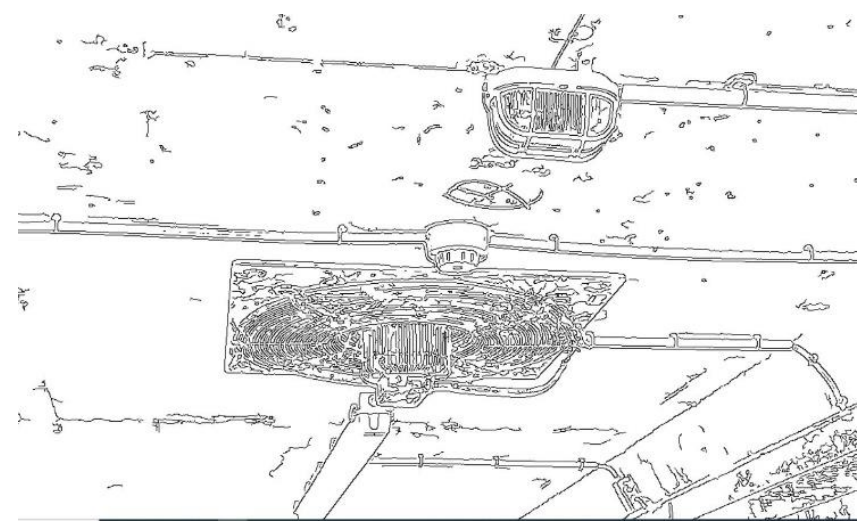

Şekil 9. Temsili yangın dedektörü, havalandırma sistemi ve aydınlatma lambasi.

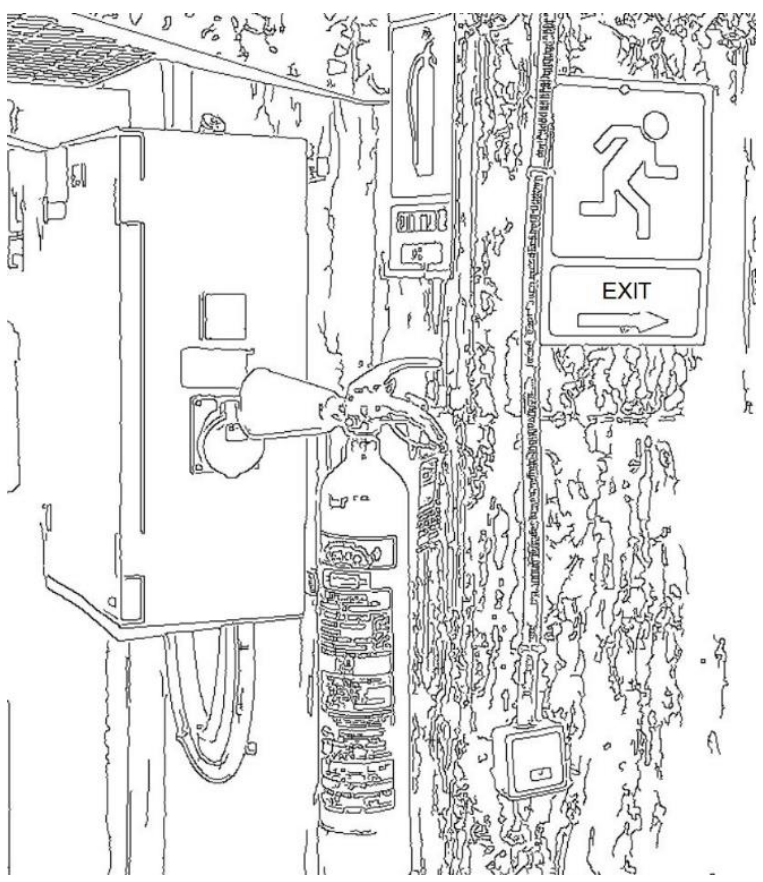

Şekil 10. Temsili acil durum telefon ve ekipmanlart.

Bir diğer önemli konu da güvenliktir. Bu tip altyapı tünelleri açılabilir betonarme kapaklı sistemler olup, kötü niyetli kişilerin tehlikesi altındadır (Canto-Perello \& Curiel-Esparza, 2006). Herhangi bir sabotaj durumunda üst kapağı tahrip edilmiş ve içi su dolmuş olabilir, kanal boyunca çalışan işçilerin bulunması durumunda sonuçlar çok vahim olabilir. $\mathrm{Bu}$ nedenle bu kanalların güvenliği ciddi anlamda tesis edilmelidir. Düzenli olarak kanallar kontrol edilmeli, güvenlik durumunu belirten raporlar düzenli olarak hazırlanmalıdır. Gaz ve duman detektörleri, kapak açılması durumunda devreye giren ve kontrol merkezini ve en yakın müdahale ekibini uyaracak alarm sistemi, güvenliği tesis etme anlamında standart uygulamalar olmalıdır (Canto-Perello vd., 2013). Ayrıca, betonarme tünelin statiği deprem dahil doğal afetlere karşı test edilmelidir (Chen vd., 2010; Yang \& Wang, 2013).

$\mathrm{Bu}$ amaçla dünyada uzun süredir sıkça uygulanan 1sıya duyarlı fiber optik kabloların kullanılması önerilmektedir. 1997 yılında Ishii vd. (1997) yaptıkları çalışmada bu sistemi test etmiş ve $2 \mathrm{~km}$ uzunluğundaki tünelde 5 metre ve 5 santigrad derece 1s1 hassasiyeti ile başarılı sonuçlar almışlardır. Günümüz teknolojisinde geliştirilmiş benzer sistemlerde daha kesin sonuçlar alınması beklenmektedir.
Fiber optik sıcaklık algılama ve izleme teknikleri inşaat mühendisliği, petrol ve gaz, enerji santralleri, yangın algılama gibi çeşitli alanlarındaki uygulamalar ile yeni olanaklar sağlamıștır (Bartholmai vd., 2013; Rajeev vd., 2013). Mevcut altyapı için uygulamada zorluklar olabileceği düşünülmekle beraber, oluşturulacak alternatif altyapı sisteminin yenilenmesi ve onarım maliyetlerinin ve kazının minimuma indirilmesi için fiber optik teknolojiden faydalanılmaktadır.

Boru hattı kanala yerleştirilmeden önce bu kabloların döşenmesi gerekmektedir, fiber optik kablolar boru hattının 10 cm altına döşenmelidir (Inaudi \& Glisic, 2008). Bazı sistemlerde ise fiber optik kablolar borunun üzerine bağlanmaktadır (Glisic \& Inaudi, 2007; Nikles vd., 2007) (Bkz. Şekil 11). Herhangi bir sızıntı ve 1sı değişimi gibi durumlarda, arızanın yeri sistem tarafindan otomatik olarak belirlenmektedir (Inaudi \& Glisic, 2005; Li vd., 2004). Boru altına ve üstüne döşenen kablolarla sızıntı olduktan sonra sistem arızayı ve yerini bilgisayar teknolojisi aracılı̆̆ 2007; Inaudi \& Glisic, 2006). Yatay Yönlü Sondaj sırasında fiber optik sensörler altyapıya entegre edilmelidir.

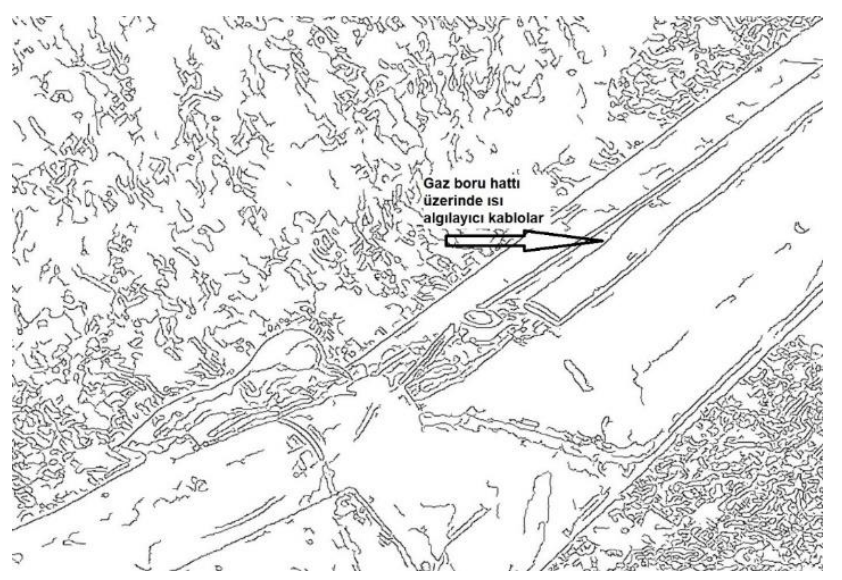

Şekil 11. Temsili gaz boru hattı üzerinde ısı algılayıcı kablolar.

Yolun her iki tarafında yerleştirilmesi düşünülen altyapı sisteminin belli noktalarda birleştirilmesi ve tek hat üzerinde devam etmesi durumunda ayrıca yan bağlantılarda kazı yapmak durumunda kalınabilmektedir. Kazı yapılmaması için (Horizontal Directional Drilling - HDD) Yatay Yönlü Sondaj (YYS) Sistemi kullanılmaktadır. Bu sistemde açık kazı yapmadan boru ve kablolar toprak altına döşenebilmektedir (Allouche vd., 2000; Tighe vd., 2002). Her aşamada üstten takip edilebilme özelliği sayesinde yeraltında bulunan mevcut yapılara ve şebekelere zarar verilmez ve istenilen noktadan girip yine istenilen noktadan çıkılabilmektedir (Willoughby, 2005) (Bkz. Şekil 12). 

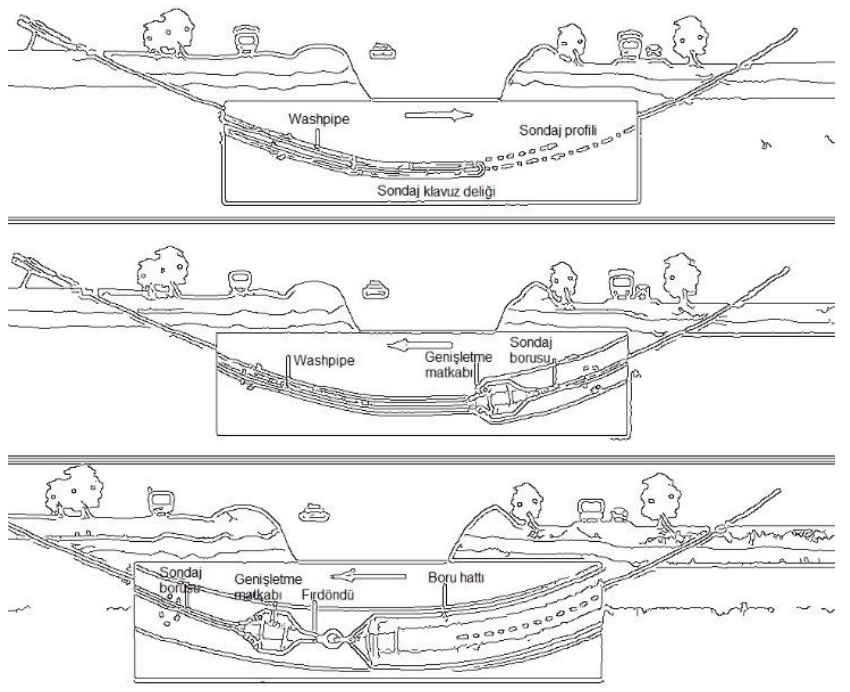

Şekil 12. Temsili yönlendirilebilir Yatay Sondaj aşamaları (Klavuz deliğin açılması, açılan deliğin genişletilmesi ve Borunun çekilmesi).

Sürdürülebilir kentsel gelişmenin sağlanabilmesi amacı ile kent formu ile altyapı maliyeti ilişkisi ele alınmalıdır. Yerleşim yerlerinin kentleşme noktasında geleceğine dair geliştirilen alternatif senaryolar kentsel teknik altyapı maliyetleri açısından CBS (Coğrafi Bilgi Sistemleri) teknolojileri kullanımı ile oluşturulabilir. Minimum maliyetli altyapı haritası CBS yardımı ile oluşturulurken, şehirleşmenin yeni başladığı bölgeler için bu çalışmalar emsal teşkil edebilir. Bununla birlikte şehirleşmenin henüz başlamadığı yerler için imara açılma aşamasında öngörülen altyapı şehir planı ile uyumlu ve maliyeti minimuma indirecek, şehir planlarında sıklıkla kullanılan ızgara desen ile altıgen desen gibi geometrik formlardan faydalanılmalıdır (Gökçen, 2006).

Önerilen kazısız altyapı ve Yatay Yönlü Sondaj (YYS) sistemlerinin ayrıntılı bir tasarımı geliştirilmeden önce, gerçek bir projeye dayalı olarak sistemin işlevselliğini test etmek için pilot araştırma yapılmalıdır. Çünkü yerel politika ve kültür, çeşitli bölgelerde sistem uygulamasını etkileyebilir. Bu noktada CBS (Coğrafi Bilgi Sistemleri) teknolojisi, altyapı tünellerinin konumu ve çevre ortamı hakkında bilgi elde etmek için potansiyel olarak sisteme entegre edilebilir. CBS entegrasyonu, yeni altyapı sistemleri hakkında yeterli uygulama pratiğine sahip olmayan saha çalışanlarına uygulamayı daha iyi anlamaları için yardımcı olacak üç boyutlu (3B) bir görünüm sağlayabilmektedir (Lee vd., 2018). Tüm yeraltı boru hatlarının derinlik, konum, boyut ve hatta boruların malzemeleri dâhil olmak üzere bir 3B görselleştirme ile gösterilebileceği açıktır. Ayrıca, eksiksiz 3B görselleştirme veri tabanı ile mühendisler, boru hattı güzergâhlarını ve kazı faaliyetlerini optimize edebilmektedirler.

Simülasyon karar vermek için güçlü bir araçtır. Yapılması öngörülen bir çalışmanın uygulanabilirliğini test etme olanağı sağlamaktadır. Karar sürecinde modeli geliştiren akademik ve uygulama noktasındaki profesyonel mühendis ekibi tarafindan, tasarım aşaması esnasında önerilen uygulamanın yapım, maliyet ve uygulama aşamaları simülasyon ile görülür ve uygulamada optimum kalite yakalanır. Akademik çerçevede tasarlanan yenilikçi altyapı sistemi çalışması proje ekibi ve belediye arasındaki etkileşimli ortak araştırma ve uygulama çalışmaları ile başarıya ulaşabilir (Keirstead \& Shah, 2013; Rehan vd., 2013).
Önerilen altyap1 sistemlerinin uygulanabilirliğini test etme olanağ1 sağlayacak ve karar vermede yardimci olacak olan bir simülasyon çalışmasında işletme ve bakım konularına ek olarak, hidrolojik, toprak malzemeleri ve yataklama koşulları gibi diğer kritik konuların da dikkate alınması gerekmektedir.

Önerilen altyapı sistemlerinin koordinasyonunu sağlayacak olan bir merkezde CBS ile simulasyon calismalarini destekleyecek veritabanı, altyapı tünelinin kendisi, ekipman ve boru hatlarına ilişkin bilgiler de dahil olmak üzere önemli miktarda bilginin depolanmasını gerektirecektir. Veritabanı ile amaçlanan hedefler; gerçek zamanlı bilgi toplama, etkili bilgi entegrasyonu ve dağıtımı, görselleştirilmiş bilgi yönetimi ve otomatik güvenlik izleme ve alarm olarak siralanabilmektedir. Oluşturulacak veritabanı, güvenlik bilgisi, ekipman bilgisi, bakım bilgisi, sözleşme bilgisi, maliyet bilgisi ve yönetim bilgisi gibi fonksiyonel modüller de içermelidir.

Önerilen çalışma, İstanbul altyapı sistemindeki karışıklığın önüne geçmek maksadı ile tüm altyapının bir araya toplandığ bir betonarme yapının tasarımı olmasının yanı sıra, başta yeni yerleşim birimleri olmak üzere tüm şehir için su getirme ve kanalizasyonda yenilikçi bir yönetim sisteminin oluşturulmasını da içermektedir. Benzer bir çalışma Mendoza-Espinosa vd.'nin (2006) araştırmalarında gri su için yapılmıştır ve planlama ekibi bir sistem modeli geliştirmiştir, gri su ve geri dönüşümlü su uygulamaları farklı senaryolar ile simüle edilmiştir. Simülatör olarak ISEE Systems tarafından geliştirilen STELLA seçilmiştir. $\mathrm{Bu}$ çalışma bizlere gri suyun değerlendirilerek su kaynaklarının tasarruflu kullanılması konusunda ilham verebilir. Karahan (2009) gri suyun arıtılarak bahçe sulama, tuvalet rezervuarları, temizlik gibi kısımlarda kullanılması durumunda, tüketilen suyun yaklaşık \%50'sinin gri su sisteminden sağlanabileceğini ortaya koymuştur.

$\mathrm{Bu}$ durumda tasarlanacak olan altyapı sisteminde ileri ya da yakın vadede uygulamaya geçilmesi durumunda geri dönüşüm suyunun taşınmasında kullanılacak borular için gerekli hacim de düşünülmelidir. Kesitin ileride genişleme gereksiminin ortaya çıkması olasılığı hesaba katılarak yeterli alan tasarlanmalıdır. Projenin gerçekleşmesi durumunda temel maliyetler, operasyonel maliyetler, verimlilik, inşaat süresi, destek ve kaynakların kullanımı, yenilikçi altyapı sistemi projesi için öncelikli olarak belirlenmesi gereken konulardır.

\section{Sonuç}

Araştırma kapsamında önerilen altyapı sistemi, şehir planı dikkate alınarak tasarlanmalıdır. Çok sayıda coğrafi veya arazi kullanım değişikliği varsa, pratik çözümler üretmek kolay değildir. Altyapı sistemi, bu topografik değişikliklerle ilgili sorunlara cevap verebilecek nitelikte farklı sistemlerin bir arada kullanılabileceği nitelikte olmalıdır. $\mathrm{Bu}$ çalışma kapsamında İstanbul için Yatay Yönlü Sondaj (YYS) sistemi önerilmiştir. Bu sistemde borular ve kablolar açık kazı yapılmadan yer altına döşenebilmektedir ve bu durum geleneksel sistemlere kıyasla işletme maliyetini düşürmektedir. Altyapı güvenliği için entegre bir fiber optik sensörün kullanılması bir diğer öneridir. Boru hattı izleme için Yatay Yönlü Sondaj sırasında fiber optik sensörler altyapıya entegre edilmelidir.

Kent planlama ile altyapı maliyetleri arasında güçlü bir ilişki vardır. CBS (Coğrafi Bilgi Sistemleri) kullanımı ile geleceğe yönelik alternatif senaryolar geliştirilebilir. CBS yardımıyla minimum maliyetli altyapı haritaları oluşturulabilir. 
$\mathrm{Bu}$ teknolojinin, İstanbul'da kentleşmenin yoğun olduğu bölgelerde sürdürülebilir kalkınmayı sağlamak için güçlü bir araç olabileceği düşünülmektedir.

Simülasyon, planlanmış bir çalışmanın fizibilitesinin test edilmesini sağlar. Karar vermek için güçlü bir araçtır. Akademik ve profesyonel mühendisler tarafından önerilen bir uygulamanın yapım, maliyet ve uygulama aşamaları karar verme sürecinde simülasyon yoluyla görselleştirilir. Önerilen sistemlerin uygulanmasından önce, coğrafya ve arazi kullanımı dahil olmak üzere birçok faktör göz önünde bulundurularak hepsinin simüle edilmesi gerekmektedir. Önerilen tekniğin uygulanması durumunda, İstanbul'un dar ve dik yokuşlu sokaklarının altyapı sorunları önemli ölçüde çözülecektir. Bu doğrultuda ilgili meslek gruplarının Lisans ve Yüksek Lisans eğitim programlarında yenilikçi altyapı tünellerinin tasarım ve uygulanmasına yönelik teknik standardizasyon ve güncelleştirmelerin müfredata dahil edilmesi önerilmektedir.

Gelecekteki araştırma çabaları, önerilen sistemi pratik bir vaka örneğine uygulayarak ve pratik alandan kapsamlı sonuçlar toplayarak önerilen sistemin doğrulanması ve onaylanmasına yönelik olabilir. Önerilen çerçeve, gelecekteki araştırmalara daha ayrıntılı ve kapsamlı bilgiler entegre edilerek geliştirilebilir. Ayrıca, bakım stratejilerinin bilimsel ve verimli bir şekilde geliştirilmesine yardımcı olmak için bu altyapı sistemine dair yeterli veri toplandıktan sonra veri madenciliği gibi diğer teknolojiler uygulanabilir.

\section{Kaynakça}

AbouRizk, S. M., Ruwanpura, J. Y., Er, K. C., \& Fernando, I. (1999). Special purpose simulation template for utility tunnel construction. In Simulation Conference Proceedings, 1999 Winter (Vol. 2, pp. 948-955). IEEE.

Allouche, E. N., Ariaratnam, S. T., \& Lueke, J. S. (2000). Horizontal directional drilling: profile of an emerging industry. Journal of Construction Engineering and Management, 126(1), 68-76.

Ariaratnam, S. T., Chan, W., \& Choi, D. (2006). Utilization of trenchless construction methods in mainland China to sustain urban infrastructure. Practice Periodical on Structural Design and Construction, 11(3), 134-141.

Ariaratnam, S. T., Lueke, J. S., \& Allouche, E. N. (1999). Utilization of trenchless construction methods by Canadian municipalities. Journal of construction engineering and management, 125(2), 76-86.

Bartholmai, M., Neumann, P. P., \& Lazik, D. (2013). Multifunctional Sensor for Monitoring of CO2 Underground Storage by Comprehensive and Spatially Resolved Measuring of Gas Concentrations, Temperature and Structural Changes. Energy Procedia, 37, 4033-4040.

Bennett, D. (2005). The Art of Precast Concrete: Colour, Texture, Expression. Berlin, Boston: Birkhäuser. Publishers for Architecture, Basel, Switzerland.

Brundtland, G. H. (1987). Our common future-Call for action. Environmental Conservation, 14(4), 291-294.

Canto-Perello, J., \& Curiel-Esparza, J. (2001). Human factors engineering in utility tunnel design. Tunnelling and Underground Space Technology, 16(3), 211-215.

Canto-Perello, J., \& Curiel-Esparza, J. (2006). An analysis of utility tunnel viability in urban areas. Civil Engineering and Environmental Systems, 23(1), 11-19.
Canto-Perello, J., Curiel-Esparza, J., \& Calvo, V. (2009). Analysing utility tunnels and highway networks coordination dilemma. Tunnelling and Underground space technology, 24(2), 185-189.

Canto-Perello, J., Curiel-Esparza, J., \& Calvo, V. (2013). Criticality and threat analysis on utility tunnels for planning security policies of utilities in urban underground space. Expert Systems with Applications, 40(11), 4707-4714.

Capitol Visitor Center Project Office, Architect of the Capitol (2005). United States Capitol Visitor Center Weekly Construction Summary. October 17, 2005. 18 Aralık 2021 tarihinde

https://web.archive.org/web/20100107044815/http://www.a oc.gov/cvc/weekly/2005/loader.cfm?csModule=security/getf ile\&pageid $=12912$ adresinden erişildi.

Chen, J., Shi, X., \& Li, J. (2010). Shaking table test of utility tunnel under non-uniform earthquake wave excitation. Soil Dynamics and Earthquake Engineering, 30(11), 1400-1416.

Curiel-Esparza, J., \& Canto-Perello, J. (2005). Indoor atmosphere hazard identification in person entry urban utility tunnels. Tunnelling and underground space technology, 20(5), 426-434.

Gagnon, M., Gaudreault, V., \& Overton, D. (2008). Age of public infrastructure: A provincial perspective. Ottawa: Statistics Canada.

Glisic, B., \& Inaudi D. (2007). Fibre Optic Methods for Structural Health Monitoring. John Wiley \& Sons, Ltd. ISBN: 978-0-470-06142-8.

Gökçen, T. (2006). "Influence of urban geometry on public investment cost of urban technical infrastructure: a case study of sewer system in Aydın, Turkey". İzmir Yüksek Teknoloji Enstitüsü, Doktora Tezi.

Hall, P., \& Pfeiffer, U. (2013). Urban future 21: a global agenda for twenty-first century cities. Routledge.

Hunt, D. V. L., Nash, D., \& Rogers, C. D. F. (2014). Sustainable utility placement via multi-utility tunnels. Tunnelling and Underground Space Technology, 39, 15-26.

Inaudi, D., \& Glisic B. (2008) "Overview of fibre optic sensing to structural health monitoring applications." 4th IAG Symposium on Geodesy for Geotechnical and Structural Engineering. LNEC, Lisbon, 2008 May 12-15.

Inaudi, D., \& Glisic, B. (2005). "Field Applications of Fiber Optic Strain and Temperature Monitoring Systems". Optoelectronic Sensor-based Monitoring in Geo-engineering, Nanjing, P.R.China, November 23-24.

Inaudi, D., \& Glisic, B. (2006). Reliability and field testing of distributed strain and temperature sensors. In Smart Structures and Materials 2006: Smart Sensor Monitoring Systems and Applications (Vol. 6167, p. 61671D). International Society for Optics and Photonics. SPIE Smart Structures and Materials Conference in San Diego. 2006 February 27- March 2, 2006.

Inaudi, D., Glisic, B., Figini, A., \& Walder, R. (2007) "Papeline Leakage Detection and Localization Using Distributed Fiber Optic Sensing". Rio Pipeline Conference \& Exposition.

Ishii, H., Kawamura, K., Ono, T., Megumi, H., \& Kikkawa, A. (1997). A fire detection system using optical fibres for utility tunnels. Fire safety journal, 29(2-3), 87-98.

Karahan, A. (2009). Gri Suyun Değerlendirilmesi. IX. Ulusal Tesisat Mühendisliği Kongresi ve Sergisi. TMMOB Makina Mühendisleri Odası. 
Keirstead, J., \& Shah, N. (2013). The Changing Role of Optimization in Urban Planning. In Optimization, Simulation, and Control (pp. 175-193). Springer New York.

Lee, P. C., Wang, Y., Lo, T. P., \& Long, D. (2018). An integrated system framework of building information modelling and geographical information system for utility tunnel maintenance management. Tunnelling and Underground Space Technology, 79, 263-273.

Li, H. N., Li, D. S., \& Song, G. B. (2004). Recent applications of fiber optic sensors to health monitoring in civil engineering. Engineering structures, 26(11), 1647-1657.

Li, P., Huang, P., Liu, Z., Du, B., \& Li, M. (2019). Experimental study on vented explosion overpressure of methane/air mixtures in manhole. Journal of hazardous materials, 374, 349-355.

Ma, B., \& Najafi, M. (2008). Development and applications of trenchless technology in China. Tunnelling and Underground Space Technology, 23(4), 476-480.

Mendoza-Espinosa, L. G., Figueroa-Nolasco, M. O., \& LopezCalva, E. (2006). Systems modeling for the planning of greywater management in new housing developments in the city of Ensenada, Baja California, Mexico. Proceedings of the Water Environment Federation, 2006(6), 6053-6066.

Nikles, M., Vogel, B., Fabien, B., Grosswig, S., Sauser, F., Luebbecke, S., Bals, A., Pfeiffer, T. (2004). "Leakage detection using fiber optics distributed temperature monitoring”. Smart Structures and Materials 2004: Smart Sensor Technology and Measurement Systems. Edited by Udd, Eric; Inaudi, Daniele. Proceedings of the SPIE, Volume 5384, pp. 18-25.

Parriaux, A., Blunier, P., Maire, P., \& Tacher, L. (2007, September). The DEEP CITY project: a global concept for a sustainable urban underground management. In 11th ACUUS International Conference, Underground Space: Expanding the Frontiers (No. CONF, pp. 255-260).

Rajeev, P., Kodikara, J., Chiu, W. K., \& Kuen, T. (2013). Distributed Optical Fibre Sensors and Their Applications in Pipeline Monitoring. Key Engineering Materials, 558, 424434.

Rehan, R., Knight, M. A., Unger, A. J. A., \& Haas, C. T. (2013). Financially sustainable management strategies for urban wastewater collection infrastructure-Development of a system dynamics model. Tunnelling and Underground Space Technology, 39, 1-14.

Riera, P., \& Pasqual, J. (1992). The importance of urban underground land value in project evaluation: a case study of Barcelona's utility tunnel. Tunnelling and underground space technology, 7(3), 243-250.

Rivard Concrete. (2014). 18 Aralık 2021 tarihinde https://rivardconcrete.com adresinden erişildi.

Rogers, C. D. F., \& Hunt, D. V. L. (2006, May). Sustainable utility infrastructure via multi-utility tunnels. In Proceedings of the Canadian Society of Civil Engineering 2006 conference, Towards a sustainable future, Calgary.

Ruiz, F. P. (2009). A precast concrete utility tunnel was the solution for one of the world's largest drug manufacturers. Precast Utility Tunnel: Eli Lilly and Co. Project. National Precast Concrete Association Indianapolis, IN 46290. 18 Aralık 2021 https://precast.org/2009/07/precast-utilitytunnel-eli-lilly-and-co-project/?fs=utility\%20tunnel adresinden erişildi.
Shahrour, I., Bian, H., Xie, X., \& Zhang, Z. (2020). Use of smart technology to improve management of utility tunnels. Applied Sciences, 10(2), 711.

Sterling, R. L. (2007). Urban underground space use planning: a growing dilemma. Urban Planning International, 6(004).

Tighe, S., Knight, M., Papoutsis, D., Rodriguez, V., \& Walker, C. (2002). User cost savings in eliminating pavement excavations through employing trenchless technologies. Canadian Journal of Civil Engineering, 29(5), 751-761.

University of Washington - Engineering Services (2017). Civil Facilities Services Design Guide Utility Tunnels and Trenches. $18 \quad$ Aralk 2021 tarihinde https://facilities.uw.edu/files/media/fsdg-02-u-utilitytunnels-trenches.pdf adresinden erişildi.

Wang, X., Tan, Y., Zhang, T., Zhang, J., \& Yu, K. (2020). Diffusion process simulation and ventilation strategy for small-hole natural gas leakage in utility tunnels. Tunnelling and Underground Space Technology, 97, 103276.

Waters, T. R., Lu, M. L., \& Occhipinti, E. (2007). New procedure for assessing sequential manual lifting jobs using the revised NIOSH lifting equation. Ergonomics, 50(11), 1761-1770.

Willoughby, D. (2005). Horizontal directional drilling: utility and pipeline applications. McGraw-Hill Education.

Wu, J., Bai, Y., Fang, W., Zhou, R., Reniers, G., \& Khakzad, N. (2021). An Integrated Quantitative Risk Assessment Method for Urban Underground Utility Tunnels. Reliability Engineering \& System Safety, 107792.

Yang, J., \& Wang, H. (2013). Seismic response analysis of shallow utility tunnel in liquefiable soils. In ICPTT 2012: Better Pipeline Infrastructure for a Better Life (pp. 16061618).

Yin, X., Liu, H., Chen, Y., Wang, Y., \& Al-Hussein, M. (2020). A BIM-based framework for operation and maintenance of utility tunnels. Tunnelling and Underground Space Technology, 97, 103252.

Zaneldin, E. K. (2007). Trenchless construction: an emerging technology in United Arab Emirates. Tunnelling and underground space technology, 22(1), 96-105.

Zhou, K., Li, F., Cai, H., Jing, Y., Zhuang, J., Li, M., \& Xing, Z. (2021). Estimation of the Natural Gas Leakage Source with Different Monitoring Sensor Networks in an Underground Utility Tunnel: from the perspectives of energy security. Energy and Buildings, 111645. 